\title{
Differentiation of Protonated Aromatic Regioisomers Related to Lignin by Reactions with Trimethylborate in a Fourier Transform Ion Cyclotron Resonance Mass Spectrometer
}

\author{
Jayalakshmi Somuramasami, ${ }^{1,3}$ Penggao Duan, ${ }^{1,4}$ Lucas M. Amundson, ${ }^{1}$ \\ Enada Archibold, ${ }^{1}$ Brian E. Winger, ${ }^{2}$ Hilkka I. Kenttämaa ${ }^{1}$ \\ ${ }^{1}$ Department of Chemistry, Purdue University, BRWN Building, 560, Oval Drive, West Lafayette, IN, 47907, USA \\ ${ }^{2}$ Eli Lilly and Company, Indianapolis, IN, USA \\ ${ }^{3}$ Merck \& Co., Inc., Union, NJ 07083, USA \\ ${ }^{4}$ Bruker Daltonics, Billerica, MA 01821, USA
}

\begin{abstract}
Several lignin model compounds were examined to test whether gas-phase ion-molecule reactions of trimethylborate (TMB) in a FTICR can be used to differentiate the ortho-, meta-, and para-isomers of protonated aromatic compounds, such as those formed during degradation of lignin. All three regioisomers could be differentiated for methoxyphenols and hydroxyphenols. However, only the differentiation of the ortho-isomer from the meta- and para-isomers was possible for hydroxyacetophenones and hydroxybenzoic acids. Consideration of the previously reported proton affinities at all basic sites in the isomeric hydroxyphenols, and the calculated proton affinities at all basic sites in the three methoxyphenol isomers, revealed that the proton affinities of the analytes relative to that of TMB play an important role in determining whether and how they react with TMB. The loss of two methanol molecules (instead of one) from the adducts formed with TMB either during ion-molecule reactions, or during sustained-off resonance irradiated collision-activated dissociation of the ion-molecule reaction products, revealed the presence of two functionalities in almost all the isomers. This finding supports earlier results suggesting that TMB can be used to count the functionalities in unknown oxygen-containing analytes.
\end{abstract}

Key words: Trimethyl borate, Methoxyphenol, Hydroxyphenol, Hydroxyacetophenone, Hydroxybenzoic acid, Ion-molecule reactions, Regioisomers, FTICR

\section{Introduction}

Tsomeric compounds often exhibit different physical and 1 chemical properties. Hence, differentiation of isomers is an important problem, and especially challenging when the isomers are components of a complex mixture. Mass spectrometry is the method of choice for analysis of complex

Correspondence to: Hilkka Kenttämaa; e-mail: hilkka@purdue.edu mixtures, such as lignin degradation products formed during the development of biofuels, since the analysis can be done without isolating and purifying the mixture components. However, mass spectrometric differentiation of isomers is often problematic since they have exactly the same molecular weight, and their fragmentation pathways are often similar. Hence, isomer differentiation by mass spectrometry is commonly based on abundance differences of dissociation products $[1,2]$. However, occasionally, unique fragmentation patterns have been observed for isomers [3]. 
In contrast to gas-phase dissociation reactions, gas-phase ion-molecule reactions provide a powerful technique for obtaining structural information for isomers [4-15]. Most often these experiments involve using an ionized reagent to probe the structure of a neutral analyte. Among many other reagents, ionized boron and phosphorus reagents have been demonstrated to be useful in the identification of isomers. For example, reactions of protonated trimethylborate (TMB) and its complexes, $\left(2 \mathrm{TMB}+\mathrm{H}-\mathrm{CH}_{3} \mathrm{OH}\right)^{+}$and $(2 \mathrm{TMB}+\mathrm{H})^{+}$, have been shown to allow differentiation of some neutral isomeric cyclic glycols and mono- and disaccharides [14]. Phosphenium ions have been employed to distinguish neutral diastereomeric hydroxysteroids, cyclic vicinal diols and cis- and trans-1,2-diaminocyclohexanes [16-18].

In contrast to the above approach, differentiation of ionized isomeric analytes by using neutral reagents has received less attention, in spite of the fact that methods that involve nearly simultaneous evaporation and ionization of the analyte, such as matrix-assisted laser desorption ionization and electrospray ionization, have become common. An example of this approach involves the use of reactions of neutral TMB with deprotonated phosphorylated carbohydrates, followed by CAD, to determine the position of the phosphate group in the carbohydrates $[19,20]$. This work has been further expanded for the quantification of isomeric mixtures of phosphorylated hexose and $N$-acetylhexosamine monosaccharides [21]. Further, hydroiodic acid has been reported to attach to neutral basic sites in polypeptide ions in the gas phase. These reactions can be used to determine the number of neutral basic sites, including lysine, arginine, histidine and N-termini [22-24]. Neutral reagents have been developed for the identification of epoxy, $\mathrm{N}$-oxide, amido, hydroxy, ether, ester, and keto functionalities in protonated mono- and polyfunctional analytes, thus facilitating isomer differentiation [4-15, 25-34]. For example, ( $N, N$-diethylamino)dimethylborane can be used to identify the protonated amido functionality [28].

In the work presented here, the utility of TMB was tested in the differentiation of protonated aromatic regioisomers in a Fourier transform ion cyclotron resonance (FTICR) mass spectrometer. TMB was chosen as the neutral reagent for this study since it has been found to be a useful reagent in earlier studies on ion-molecule reactions of protonated analytes. Four sets of isomeric model compounds related to lignin were examined.

\section{Experimental}

The experiments were performed in two different dual-cell FTICR instruments, an Extrel Model FTMS 2001 and a Finnigan model FTMS 2001, each equipped with an Odyssey data station. These instruments contain a dual cell consisting of two identical 2 -in. cubic cells separated by a conductance limit plate. The conductance limit plate has a 2-mm hole in the center for the transfer of ions from one side into the other. The conductance limit plate and the two end trapping plates were maintained at $+2.0 \mathrm{~V}$ in both the instruments unless otherwise stated. In the Extrel FTMS 2001 mass spectrometer, the dual cell is aligned collinearly with the field of a $3 \mathrm{~T}$ superconducting magnet operated at $\sim 2.7 \mathrm{~T}$, and it is differentially pumped by two Balzers turbomolecular pumps $(330 \mathrm{~L} / \mathrm{s})$, each backed by an Alcatel 2012 mechanical pump. In the Finnigan FTMS 2001 mass spectrometer, the dual cell is aligned collinearly with the field of a $3 \mathrm{~T}$ superconducting magnet, and it is differentially pumped by two Edwards Diffstak 160 diffusion pumps (700 L/s), each backed by an Alcatel 2012 mechanical pump. A nominal baseline pressure of less than $1 \times 10^{-9}$ Torr was measured for both instruments by BayardAlpert ionization gauges located on each side of the dual cells. Liquid samples were introduced into the instruments either by using a batch inlet system equipped with Andonian leak valves or via a Varian leak valve. In the Extrel FTMS 2001 mass spectrometer, a manual solids probe was used to introduce solid samples into the instrument, whereas in the Finnigan FTMS 2001 mass spectrometer, an automatic solids probe was used to introduce solid samples.

All chemicals were purchased from the Sigma-Aldrich Company and used without further purification. The analytes were protonated by self-chemical ionization (self-CI). This was achieved by allowing the fragment ions and the molecular ion generated upon electron ionization (EI) of the neutral analyte react with the neutral analyte for a certain period of time (1-8 s). Typical ionization parameters were 0.03-2.0 s electron beam time, $25-70 \mathrm{eV}$ electron energy, and $8.0 \mu \mathrm{A}$ filament current. Nominal base pressure of the neutral reagents varied between $4.0 \times 10^{-8}$ and $6.0 \times 10^{-8}$ Torr, as measured by the ion gauges. All the ions in the other side of the dual cell were removed prior to ion transfer by changing the remote trapping plate voltage from $+2.0 \mathrm{~V}$ to $2.0 \mathrm{~V}$ for $12 \mathrm{~ms}$. The protonated analyte was transferred into the other cell by grounding the conductance limit plate $(95-125 \mu \mathrm{s})$. The transferred ions were cooled for about one second by allowing IR emission [35] and by collisions with argon present at about $10^{-5}$ Torr. The protonated analyte was isolated by using a stored-waveform inverse Fourier transform [36, 37] (SWIFT) excitation pulse to eject all unwanted ions, and allowed to react with TMB (reaction times were from 0.05 to about $500 \mathrm{~s}$ ).

Some of the reaction products were further probed by SWIFT isolation followed by off-resonance irradiated collision-activated dissociation (SORI-CAD) [38]. SORICAD experiments utilized off-resonance excitation of the isolated ion at a frequency $\pm 1000 \mathrm{~Hz}$ off the cyclotron frequency of the ion. This experiment was carried out for about $1 \mathrm{~s}$ in the presence of an inert gas $\left(\sim 10^{-5}\right.$ Torr of argon).

During the ion-molecule reactions, the neutral reagent (TMB) was present at a constant pressure and its concentration was in excess of that of the reactant ions. Hence, these reactions follow pseudo-first order kinetics, which 
allows for the derivation of the second-order reaction rate constants $\left(\mathrm{k}_{\exp }\right)$ from semilogarithmic plots of the relative abundances of the reactant ions versus reaction time and the concentration of the neutral reagent [1618]. This concentration was determined from the measured pressure change when the neutral reagent was introduced into the instrument. The uncertainty in the pressure readings of the ion gauge used in this study was corrected by measuring the rate of the highly exothermic electron-transfer reaction between argon radical cation and the neutral reagent (TMB). It can be assumed that this reaction proceeds at the collision rate $\left(\mathrm{k}_{\text {collision }}\right)$, which can be calculated [39-42]. Any reaction occurring at collision rate has $100 \%$ efficiency. Hence, this measurement yielded a correction factor for the pressure readings. The accuracy of the measured rate constants is estimated to be about $50 \%$, with the precision estimated to be better than $10 \%$.

The theoretical collision rate constants $\left(\mathrm{k}_{\text {coll }}\right)$ were obtained by using a parameterized trajectory theory [39-42]. The efficiency of each reaction (the fraction of collisions that leads to reaction) is given by $\mathrm{k}_{\mathrm{exp}} / \mathrm{k}_{\text {coll }}$.

After reactions, all ions were excited for detection by using chirp excitation at a bandwidth of $2.7 \mathrm{MHz}$, amplitude of $124 \mathrm{~V}_{p-p}$ and a sweep rate of $3200 \mathrm{~Hz} \mu \mathrm{s}^{-1}$. Background spectra were recorded by removing the ion of interest by SWIFT ejection prior to reaction or SORI-CAD. All the spectra were background corrected by subtracting the background spectra from the reaction spectra. All spectra were recorded as $128 \mathrm{k}$ data points and by using one zero-fill prior to Fourier transform.

All theoretical energies reported in this work were calculated with Gaussian 03, Revision C.02, suite of programs [43]. Geometry optimizations and vibrational frequency calculations were performed using density functional theory at the B3LYP/6-31G(d) level. The PAs of the analytes were calculated by using protonated methanol or benzene (depending on the protonation site in the analyte; methanol was used for protonation on an oxygen atom and benzene for a carbon atom) as the Brønsted acid in an isodesmic reaction scheme. In order to validate the chosen level of theory, benzene was used as the reference to calculate the PA of phenol (carbon 4 in the ring was identified as the most basic site) to be $194.4 \mathrm{kcal} / \mathrm{mol}$, which is in an excellent agreement with the known experimental value $(195.3 \mathrm{kcal} / \mathrm{mol})$. The same was found to be true for anisole, whose calculated PA (at the most basic site, carbon 4 in the aromatic ring) is $198.7 \mathrm{kcal} /$ mol, while the known experimental value is $200.7 \mathrm{kcal} /$ mol. All stationary points were confirmed to have the correct number of imaginary frequencies by vibrational analysis. All theoretical energies are presented at $0 \mathrm{~K}$ and include zero-point vibrational energy corrections.

\section{Results and Discussion}

\section{Reactions of Protonated Regioisomers with TMB}

Reactions of TMB with several protonated regioisomeric lignin model compounds, i.e., methoxyphenols, hydroxyphenols, acetophenones, and hydroxybenzoic acids, were studied in a FTICR mass spectrometer. Almost all of the protonated analytes studied react with TMB by addition/ methanol elimination (referred to as derivatization of a functionality), or addition/elimination of two methanol molecules (referred to as double derivatization). The mechanism of these reactions is likely the same as that proposed earlier for the reactions of protonated oxygencontaining analytes with boron reagents [15]. Hence, the first step involves proton transfer from the protonated analyte to the basic methoxy group of TMB. This is followed by addition of the now-neutral analyte to the boron atom in protonated TMB, and elimination of a methanol molecule (Scheme 1). The derivatized analytes can be easily identified based on the unique boron isotope ratio $(25 \%$ of ${ }^{10} \mathrm{~B}$ relative to ${ }^{11} \mathrm{~B}$ ). ortho-Isomers of all of the analytes studied showed different reactivity from their meta- and para-isomers. For methoxyphenols and hydroxyphenols, all the regioisomers display different reactivity and can be distinguished. These analytes will be discussed first.

\section{Differentiation of Regioisomers of Protonated Methoxyphenols and Hydroxyphenols}

\section{Methoxyphenols}

Regioisomeric methoxyphenols produce similar electron ionization mass spectra. Previously, they were differentiated

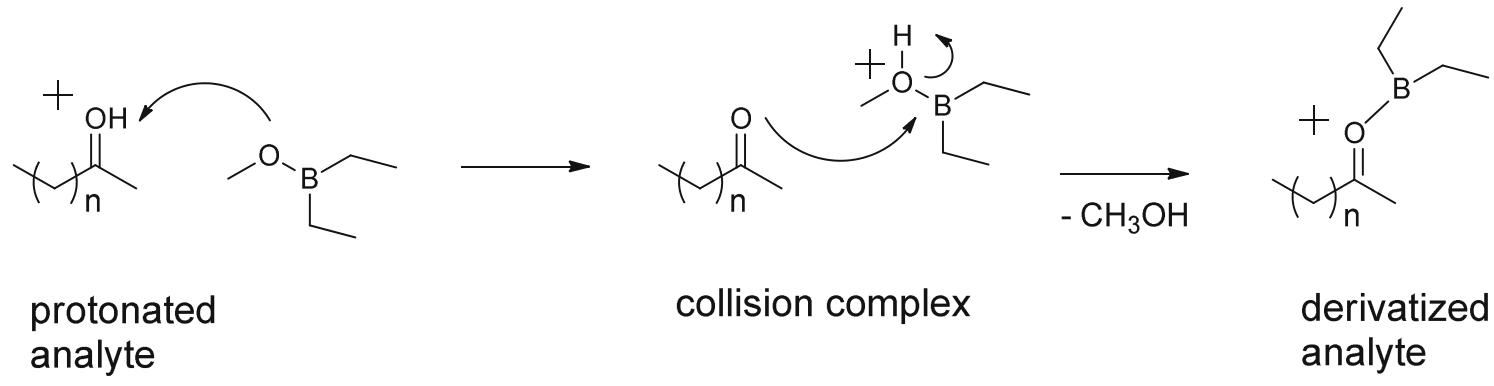

Scheme 1. 
by gas-phase reactions with iron(I) ion in an FTICR mass spectrometer [45]. However, this method requires specialized equipment that is not commercially available. In this study, protonated ortho-methoxyphenol was found to react with one molecule of TMB via addition and elimination of two methanol molecules, which leads to the derivatization of both functional groups in this analyte. However, the paraisomer consumes two molecules of TMB for complete derivatization (elimination of a total of two methanol molecules). The meta-isomer is unreactive toward TMB (Table 1, Fig. 1). Hence, TMB can be used to distinguish these three regioisomers.

In order to account for the differences in reactivity observed for the three protonated methoxyphenol isomers, molecular orbital calculations were performed to estimate the proton affinities (PA) of each basic site in the three isomers at the B3LYP/6-31 G(d) level of theory (Fig. 2; Table 2). These calculations predict that these aromatic analytes are protonated at the ring, not a heteroatom. For all isomers, protonation at any of the carbons was found to be more favorable than protonation at the methoxy group (with one exception: protonation at the 3-position in the ring of meta-methoxyphenol is less favorable than protonation at the methoxy group), which is more favorable than protonation of the hydroxyl functionality.

The PA of the meta-isomer is about $13 \mathrm{kcal} / \mathrm{mol}$ higher (208 kcal/mol) than that of TMB (195 kcal/mol [15]). Hence, the lack of reactivity of this protonated regioisomer toward TMB may be attributed to the large PA difference between the two, which hinders the initial step of the reaction sequence, proton transfer. Previous studies on reactions of protonated amines and some protonated amides with diethylmethoxyborane $[15,26-29,34]$ suggested that when the PA of the analyte is greater than that of DEMB, the proton abstraction/nucleophilic addition becomes concerted and takes place via a single transition state. Further, the higher the PA of the analyte compared to that of the boron reagent, the greater the energy of this transition state.

Though the PAs of the ortho- and para-methoxyphenols [PA of ortho-: $200 \mathrm{kcal} / \mathrm{mol}$; PA of para-: $197 \mathrm{kcal} / \mathrm{mol}$; calculated at the B3LYP/6-31 G(d) level of theory] are still higher by 5 and $2 \mathrm{kcal} / \mathrm{mol}$, respectively, than that of TMB $(195 \mathrm{kcal} / \mathrm{mol})$, reactions were observed for these protonated regioisomers. The energy gained upon formation of the collision complex of the protonated analyte and TMB allows these complexes to overcome the transition state of the reaction. Complexation energies typically lie between 5 and $20 \mathrm{kcal} / \mathrm{mol}$.

Schemes 2 and 3 depict the proposed mechanisms for the derivatization of both the functional groups in protonated ortho- and para-methoxyphenols. The reaction sequence proposed for the ortho-isomer involves abstraction of a proton from the ring of the ring-protonated isomer by TMB, followed by nucleophilic addition of the analyte to the boron center and elimination of a methanol molecule (Scheme 2). The proximity of the two functional groups in this isomer allows the second derivatization step to occur intramolecularly. However, this is not the case for the para-isomer. The

Table 1. Derivatization Products ${ }^{\mathrm{a}}$ ( $\mathrm{m} / \mathrm{z}$ Values and Formation Reactions) Formed in Reactions Between Protonated Regioisomers and TMB (PA=195 kcal/mol)

\begin{tabular}{|c|c|c|c|}
\hline Analyte $\left(m / z\right.$ of $\left.(\mathrm{M}+\mathrm{H})^{+}\right)$ & $\mathrm{PA}(\mathrm{kcal} / \mathrm{mol})$ & Product ions $(m / z)^{\mathrm{a}}$ & SORI-CAD of singly derivatized analyte \\
\hline ortho-Methoxyphenol (125) & $200^{\mathrm{b}}$ & $\begin{array}{l}\text { Adduct }-\mathrm{CH}_{3} \mathrm{OH}(197) \\
\text { Adduct }-2 \mathrm{CH}_{3} \mathrm{OH}(165)\end{array}$ & $\mathrm{N} / \mathrm{A}^{\mathrm{c}}$ \\
\hline meta-Methoxyphenol (125) & $208^{\mathrm{b}}$ & No reaction & $\mathrm{N} / \mathrm{A}^{\mathrm{c}}$ \\
\hline para-Methoxyphenol (125) & $197^{\mathrm{b}}$ & $\begin{array}{l}\text { Adduct }-\mathrm{CH}_{3} \mathrm{OH}(197) \\
\text { Adduct }+\mathrm{TMB}-2 \mathrm{CH}_{3} \mathrm{OH}(269)\end{array}$ & $\mathrm{N} / \mathrm{S}^{\mathrm{d}}$ \\
\hline ortho-Hydroxyphenol (catechol) (111) & $197^{\mathrm{e}}$ & $\begin{array}{l}\text { Adduct }-\mathrm{CH}_{3} \mathrm{OH}(183) \\
\text { Adduct }+\mathrm{TMB}-2 \mathrm{CH}_{3} \mathrm{OH}(255) \\
\text { Adduct }(215)\end{array}$ & $\mathrm{N} / \mathrm{S}^{\mathrm{d}}$ \\
\hline meta-Hydroxyphenol (resorcinol) (111) & $205^{\mathrm{e}}$ & Adduct $-\mathrm{CH}_{3} \mathrm{OH}(183)$ & $\mathrm{N} / \mathrm{S}^{\mathrm{d}}$ \\
\hline para-Hydroxyphenol (hydroquinone) (111) & $193^{\mathrm{e}}$ & $\begin{array}{l}\text { Adduct }-\mathrm{CH}_{3} \mathrm{OH}(183) \\
\text { Adduct }+\mathrm{TMB}-2 \mathrm{CH}_{3} \mathrm{OH}(255)\end{array}$ & $\mathrm{N} / \mathrm{S}^{\mathrm{d}}$ \\
\hline ortho-Hydroxyacetophenone (137) & $214^{\mathrm{b}}$ & No reaction & $\mathrm{N} / \mathrm{A}^{\mathrm{c}}$ \\
\hline meta-Hydroxyacetophenone (137) & $207^{\mathrm{b}}$ & Adduct $-\mathrm{CH}_{3} \mathrm{OH}(209)$ & Adduct $-2 \mathrm{CH}_{3} \mathrm{OH}(177)$ \\
\hline para-Hydroxyacetophenone (137) & $211^{\mathrm{b}}$ & Adduct $-\mathrm{CH}_{3} \mathrm{OH}(209)$ & Adduct $-2 \mathrm{CH}_{3} \mathrm{OH}(177)$ \\
\hline ortho-Hydroxybenzoic acid (139) & Not available & $\begin{array}{l}\text { Adduct }-\mathrm{CH}_{3} \mathrm{OH}(211) \\
\text { Adduct }+\mathrm{TMB}-2 \mathrm{CH}_{3} \mathrm{OH}(283) \\
\text { Adduct }+\mathrm{TMB}-3 \mathrm{CH}_{3} \mathrm{OH}(251)\end{array}$ & $\mathrm{N} / \mathrm{S}^{\mathrm{d}}$ \\
\hline meta-Hydroxybenzoic acid (139) & Not available & Adduct $-\mathrm{CH}_{3} \mathrm{OH}(211)$ & $\begin{array}{l}\text { Adduct }-2 \mathrm{CH}_{3} \mathrm{OH}(179) \\
\text { Adduct }-\mathrm{CH}_{3} \mathrm{OH}-\mathrm{HOB}\left(\mathrm{OCH}_{3}\right)_{2}(121)\end{array}$ \\
\hline para-Hydroxybenzoic acid (139) & Not available & Adduct $-\mathrm{CH}_{3} \mathrm{OH}(211)$ & $\begin{array}{l}\text { Adduct }-2 \mathrm{CH}_{3} \mathrm{OH}(179) \\
\text { Adduct }-\mathrm{CH}_{3} \mathrm{OH}-\mathrm{HOB}\left(\mathrm{OCH}_{3}\right)_{2}(121)\end{array}$ \\
\hline
\end{tabular}



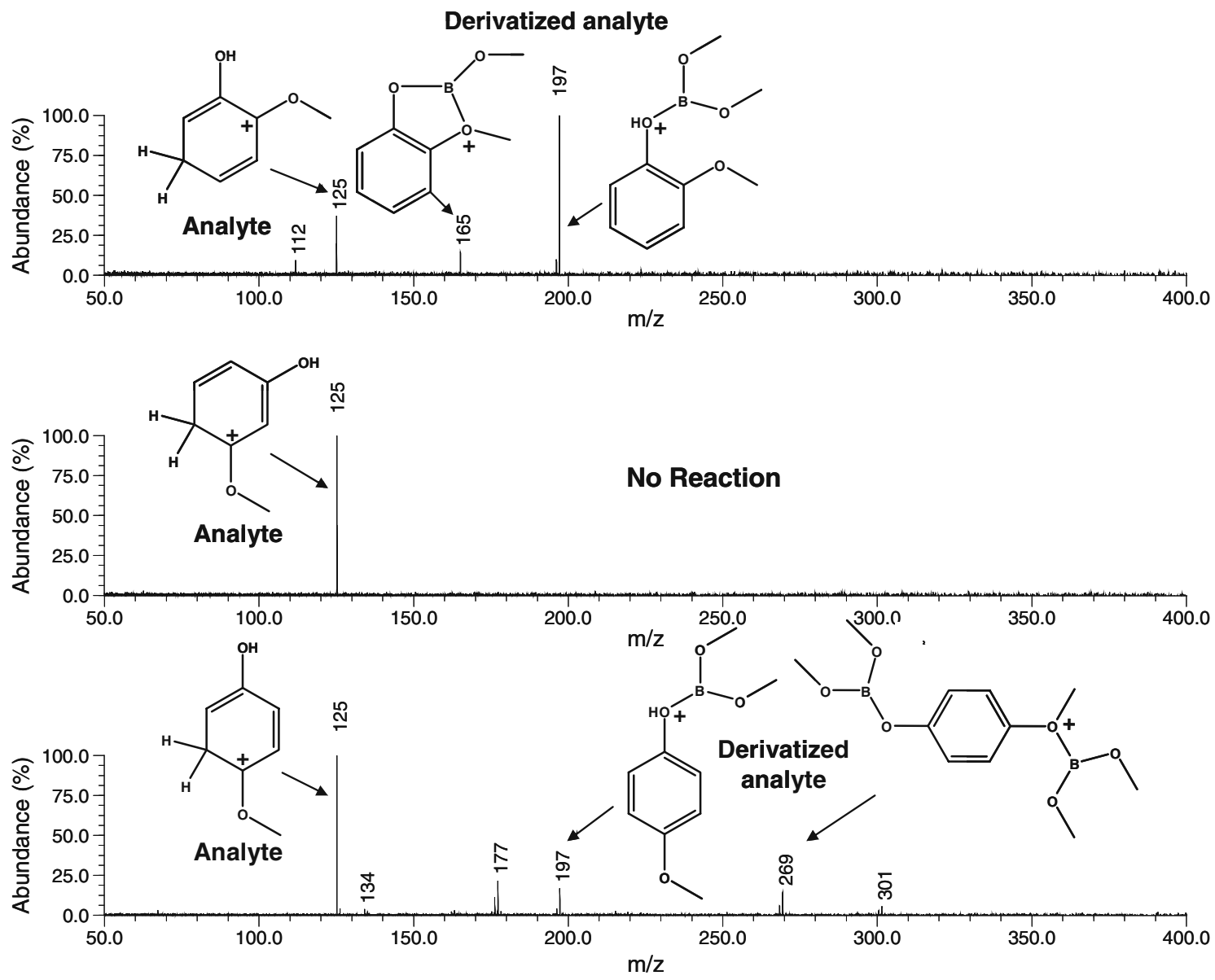

Figure 1. Mass spectra measured after reactions of TMB (MW 104) with protonated ortho-, meta-, and para-methoxyphenols for 18, 500, and $20 \mathrm{~s}$. Different behavior is observed for each one of the isomers, thus aiding in their differentiation. The ion of $\mathrm{m} / \mathrm{z} 177$ in the bottom spectrum appears to contain two boron atoms, and hence is likely to be either the $\left(\mathrm{MH}^{+}+2 \mathrm{~B}(\mathrm{OMe})_{3}-\right.$ $2 \mathrm{MeOH}-2 \mathrm{MeOMe})$ ion or alternatively the $\left(\mathrm{MH}^{+}+2 \mathrm{~B}(\mathrm{OMe})_{3}-3 \mathrm{MeOH}-\mathrm{MeOMe}-\mathrm{CH}_{2} \mathrm{O}\right)$ ion

distance between its functionalities prevents an intramolecular derivatization. Instead, the second derivatization involves a second TMB molecule. The first derivatization likely takes place at the hydroxyl group (Scheme 3) since this leads to generation of an acidic hydrogen that can be abstracted by the second TMB molecule, followed by the second derivatization reaction. This mechanism is similar to one proposed for the consecutive reactions of protonated diols with TMB [15].

\section{Hydroxyphenols}

Differentiation of hydroxyphenol regioisomers has proven challenging [46]. Hence, they provide a good test case for the methodology discussed here. Each of the three protonated hydroxyphenol regioisomers (protonated on the benzene ring [44]; the ipso position was found to be substantially less basic than the two most basic sites in each molecule) react differently with TMB (Table 1). The orthoand para-isomers undergo complete derivatization via reactions with two molecules of TMB, just like the paramethoxyphenol. As mentioned above, the mechanism likely involves proton abstraction by TMB followed by nucleophilic addition of the neutral analyte at the boron center with a concomitant methanol loss. The derivatization of the first hydroxyl group generates an acidic hydrogen, which gets abstracted by a second TMB molecule, resulting in the derivatization of the second hydroxyl group (just like for para-methoxyphenol). Similar reactivity has been observed [15] for protonated diols toward TMB and protonated polyols toward diethylmethoxyborane [27]. The protonated ortho-hydroxyphenol does not undergo a second derivatization reaction with the first added TMB molecule. One possible explanation may be the formation of an intramolecular hydrogen bond that stabilizes the first derivatization product (Scheme 4). Instead of an intramolecular proton transfer and second methanol elimination, a proton is abstracted by a second molecule of TMB (Scheme 4), leading to double derivatization. In addition to the double derivatization, the ortho-isomer forms a 
(a)

Optimized structure for protonated ortho-methoxyphenol:

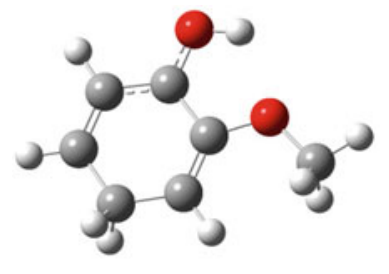

(b)

Optimized structure for protonated meta-methoxyphenol:

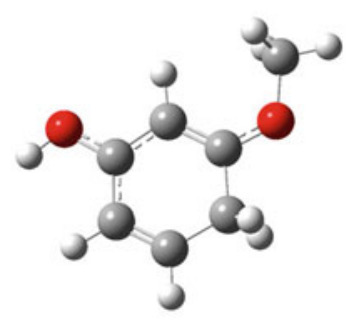

(c)

Optimized structure for protonated para-methoxyphenol:

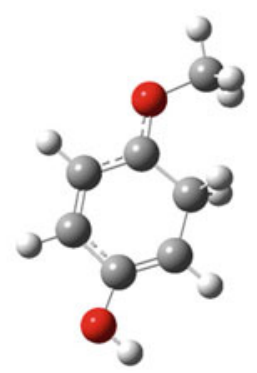

Figure 2. Optimized (B3LYP/6-31G(d)) structures of the most stable regioisomers and conformers of (a) orthomethoxyphenol, (b) meta-methoxyphenol and (c) paramethoxyphenol

stable adduct with TMB, possibly as shown in Scheme 4 . This finding suggests that the stabilizing hydrogen bond extends the lifetime of the adduct enough to allow stabilization by emission of IR light. Formation of a stable adduct was not observed for the para-isomer (or any other analyte studied); hence, this allows the differentiation of the ortho- and para-isomers.

In contrast to the ortho- and para-isomers, protonated $m e t a$-isomer forms only the first derivatization product. The lack of formation of the second derivatization product may arise from the high PA of this analyte. The meta-isomer is the most basic of the isomeric hydroxyphenols (PA $205 \mathrm{kcal} /$ mol [44]; Table 1). Since the PA of the meta-isomer is about $10 \mathrm{kcal} / \mathrm{mol}$ greater than that of TMB, the first derivatization reaction is very slow (efficiency $=\sim 0.045 \%$ ) compared, for example, to the reaction of the protonated para-isomer (efficiency 33\%). Hence, the formation of the doubly derivatized analyte is likely to be too slow to be observed, especially since the PA of the conjugate base of the singly derivatized analyte is likely to be even greater than that of the underivatized analyte.

\section{Differentiation of the ortho-Isomers} from the meta- and para-Isomers of Protonated Hydroxyacetophenones and Hydroxybenzoic Acids

\section{Hydroxyacetophenones}

Based on literature, ion-molecule reactions of the methoxymethyl cation with the three regioisomeric hydroxyacetophenones allow the distinction of the ortho-isomer from the other two [47]. It was of interest to examine whether a better distinction can be achieved by the method discussed here. Protonated meta- and para-hydroxyacetophenones react with TMB to form a singly derivatized analyte while the ortho-isomer is unreactive (Table 1). PA calculations at the B3LYP/6-31G(d) level of theory yielded a PA of $214 \mathrm{kcal} /$ mol for the ortho-isomer (meta-: PA $207 \mathrm{kcal} / \mathrm{mol}$; para-: PA $211 \mathrm{kcal} / \mathrm{mol}$; protonation occurs at the carbonyl functionality). This value is about $19 \mathrm{kcal} / \mathrm{mol}$ greater than that of TMB (PA $195 \mathrm{kcal} / \mathrm{mol}$ ), which explains the lack of reactivity of this isomer. The observation of reactivity for the para- and meta-isomers, with PA of 211 and $207 \mathrm{kcal} / \mathrm{mol}$, respectively, but not for the meta-methoxyphenol discussed above (PA $208 \mathrm{kcal} / \mathrm{mol}$ ), is not clear at this time. It is possible that the solvation energy provided by TMB to these protonated hydroxyacetophenones is greater than for the protonated meta-methoxyphenol, thus allowing for more endothermic reactions to take place.

The meta- and para-hydroxyacetophenone isomers undergo a single derivatization reaction with TMB. The lack of a second derivatization indicates either that the observed derivatization takes place at the carbonyl oxygen, which does not lead to an acidic hydrogen needed for second derivatization, or that the PA of the conjugate base of the derivatized analyte is too high for proton transfer to a second TMB molecule to occur. However, the singly derivatized meta- and para-isomers lose a second molecule of methanol upon collisional activation (SORI-CAD), thus undergoing derivatization of the second functional group. The energy deposited into the singly derivatized analyte during SORICAD appears to be sufficient to break the B-O bond, leading to the formation of a neutral meta- or parahydroxyacetophenone and a dimethoxyborenium ion. The nucleophilic hydroxyl oxygen then may attack the electrophilic boron in the dimethoxyborenium ion while these two species are still in the collision complex, thus generating an acidic hydrogen. This is followed by the migration of the proton to one of the methoxy groups attached to the boron center, leading to elimination of the second methanol molecule (Scheme 5). Support for this mechanism was 
Table 2. Calculated PAs of ortho-, meta-, and para-Methoxyphenols (B3LYP/6-31G(d) Level of Theory)

ortho-Methoxyphenol:<smiles>COc1ccccc1O</smiles>

\begin{tabular}{|l|l|}
\hline \multicolumn{1}{|c|}{ Proton at } & \multicolumn{1}{c|}{ Proton Affinities (kcal/mol) } \\
\hline $\mathrm{OH}$ & 186.5 \\
\hline $\mathrm{OCH}_{3}$ & 191.1 \\
\hline Ring C (a) & 195.9 \\
\hline Ring C (b) & 196.8 \\
\hline Ring C (c) & 199.9 \\
\hline Ring C (d) & 193.3 \\
\hline
\end{tabular}

meta-Methoxyphenol:<smiles>COc1cccc(O)c1</smiles>

\begin{tabular}{|l|l|}
\hline \multicolumn{1}{|c|}{ Proton at } & \multicolumn{1}{c|}{ Proton Affinities (kcal/mol) } \\
\hline $\mathrm{OH}$ & 181.5 \\
\hline $\mathrm{OCH}_{3}$ & 188.4 \\
\hline Ring C (a) & 206.0 \\
\hline Ring C (b) & 207.8 \\
\hline Ring C (c) & 182.3 \\
\hline Ring C (d) & 208.1 \\
\hline
\end{tabular}

para-Methoxyphenol:<smiles>COc1ccc(O)cc1</smiles>

\begin{tabular}{|l|l|}
\hline \multicolumn{1}{|c|}{ Proton at } & \multicolumn{1}{c|}{ Proton Affinities (kcal/mol) } \\
\hline $\mathrm{OH}$ & 183.4 \\
\hline $\mathrm{OCH}_{3}$ & 190.2 \\
\hline Ring C (a) & 196.7 \\
\hline Ring C (b) & 195.7 \\
\hline Ring C (c) & 193.4 \\
\hline Ring C (d) & 196.2 \\
\hline
\end{tabular}

obtained by allowing protonated acetophenone react with $\mathrm{TMB}$, isolating the derivatized product, and subjecting it to CAD. Loss of acetophenone to yield the dimethoxyborenium ion $(\mathrm{m} / \mathrm{z} 73)$ and formation of the benzyl cation ( $\mathrm{m} / \mathrm{z}$ 91) dominate. No methanol loss was observed. Hence, the hydroxyl group in hydroxyacetophenone must be involved in methanol elimination.

\section{Hydroxybenzoic Acids}

The EI mass spectra of the meta- and para-hydroxybenzoic acid regioisomers are identical, and that of the ortho-isomer is similar [48]. However, these regioisomers have been distinguished by charge stripping of $(\mathrm{M}-\mathrm{H})^{-}$ions [49]. Since these experiments are not commonly accessible, other 


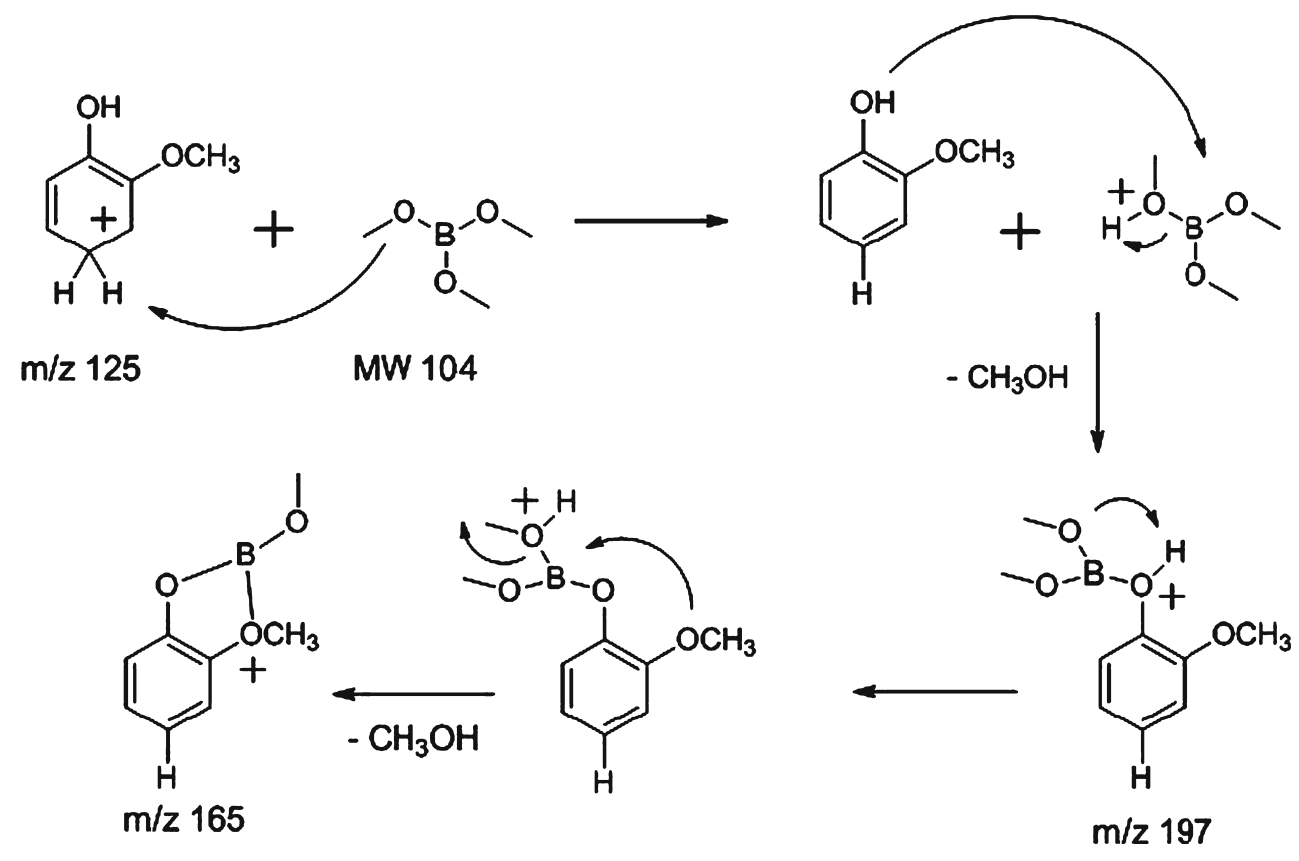

Scheme 2.<smiles>CO[C@H]1C=CC(O)=C[CH+]1</smiles>

$\mathrm{H}^{+}$migration

$+$<smiles>COB(C)C</smiles><smiles>O</smiles>
MW 104 $\mathrm{m} / \mathrm{z} 125$<smiles>COc1ccc(OC)cc1</smiles><smiles>CO[B-](C)(C)[B-](C)(OC)OC</smiles><smiles>COB(OC)Oc1ccc(OC)cc1</smiles>

$\mathrm{m} / \mathrm{z} 269$<smiles>COB(OC)Oc1ccc([B-](C)B(OC)OC)cc1</smiles><smiles>COB(OC)Oc1ccc(OC)cc1</smiles>

Scheme 3. 
<smiles>COB(OC)OB(OC)OC(C)(C)C</smiles>

$\mathrm{m} / \mathrm{z} 111$
MW 104<smiles>CCOB(OC)OC</smiles>

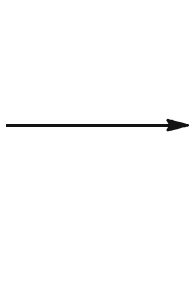<smiles>[Z16]c1ccccc1OPO[B-](C)(OC)OC</smiles><smiles>COCCOC</smiles><smiles>COBOc1ccccc1B(OC)OB(OC)OC</smiles>

$\mathrm{m} / \mathrm{z} 255$<smiles>COB(OC)Oc1ccccc1O</smiles><smiles>COB1OCOc2ccccc2O1</smiles>

$\mathrm{m} / \mathrm{z} 183$

Scheme 4.

methods are of interest. The ortho-hydroxybenzoic acid undergoes one derivatization with the first TMB molecule, and (surprisingly) two additional ones with a second TMB molecule. This reactivity may be explained in the same way as that of ortho-hydroxybenzoic acid (Scheme 4). Steric hindrance in the doubly derivatized analyte likely drives the last intramolecular methanol elimination. Similar intramolecular methanol loss was observed in an earlier study for reactions of protonated diols with TMB [15].

The reactions of the meta- and para-isomers yield only singly derivatized products, just as observed for the metaand para-isomers of protonated hydroxyacetophenones. However, the PAs of the hydroxybenzoic acids are likely to be much smaller than those of the hydroxyacetophenones. Since only a single derivatization was observed for the metaand para-isomers, the functional group that was derivatized is likely the carboxylic acid group that can form a stabilizing hydrogen bond with the borane moiety (Scheme 6), just like the protonated ortho-hydroxyphenol (Scheme 4), which prevents further derivatization due to the lack of acidic protons. Upon SORI-CAD, the singly derivatized meta- and para-isomers lose a second methanol molecule, thus undergoing derivatization of the second functionality, just like the meta- and para-hydroxyacetophenones. However, they also lose $\mathrm{O}=\mathrm{B}\left(\mathrm{OCH}_{3}\right)_{2}$, possibly as shown in Scheme 6. This fragmentation may allow the identification of meta- and para-benzoic acid moieties in unknown compounds, since the ortho-benzoic acid, methoxyphenols, hydroxyphenols, and hydroxyacetophenones do not show this loss.

In summary, for protonated hydroxyacetophenones and hydroxybenzoic acids, the ortho-isomer shows different reactivity from its meta- and para-counterparts upon ion- molecule reactions with TMB. However, the meta- and para-isomers of both analytes display the same reactivity.

\section{Conclusions}

A mass spectrometric method was tested for the differentiation of protonated aromatic regioisomers by using ionmolecule reactions with trimethylborate (TMB) in a Fouriertransform ion cyclotron resonance (FTICR) mass spectrometer. Several lignin model compounds were examined. The proton affinity (PA) differences between the analytes and TMB were found to play a key role in the observed reactivity. Molecular orbital calculations performed at the B3LYP/6-31G(d) level of theory on methoxyphenols indicate that these aromatic compounds are protonated at the benzene ring rather than the functional groups. The same finding has been published earlier for the three isomeric hydroxyphenols [47]. However, the hydroxyacetophenones protonate on the carbonyl functionality.

The ortho-, meta-, and para-isomers of methoxyphenols and hydroxyphenols react differently with TMB, which facilitates their differentiation. The meta-methoxyphenol has a greater PA than any of its isomers and any of the hydroxyphenol isomers. This PA is much greater than that of TMB. Hence, no reaction was observed between protonated meta-methoxyphenol and TMB. The PA of the metahydroxyphenol is also high, and only a very slow single derivatization (efficiency $\sim 0.045 \%$ ) was observed with TMB. However, all the ortho- and para-isomers undergo double derivatization with TMB, which reveals the presence of two functionalities. The ortho- and para-isomers of methoxyphenols can be differentiated based on the number 
J. Somuramasami, et al.: Ion/Molecule Reactions with Trimethyl Borate

1049<smiles>CCCCOB(OC)OC</smiles>

$\mathrm{m} / \mathrm{z} 111$

MW 104

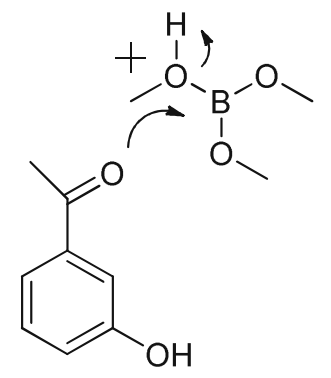

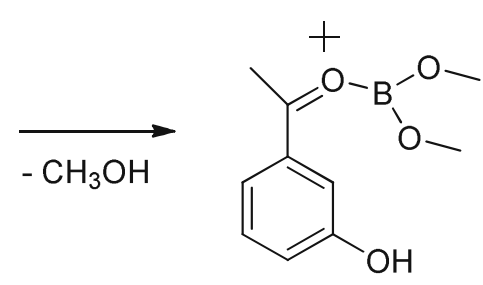

$\mathrm{m} / \mathrm{z} 209$
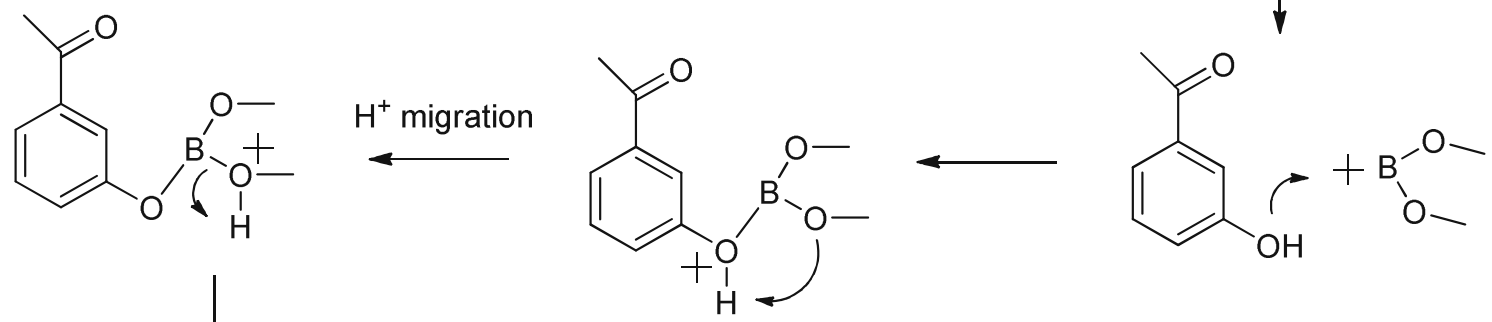

Scheme 5.<smiles>COB(OC)OC1(c2cccc(O)c2)CCCO1</smiles>

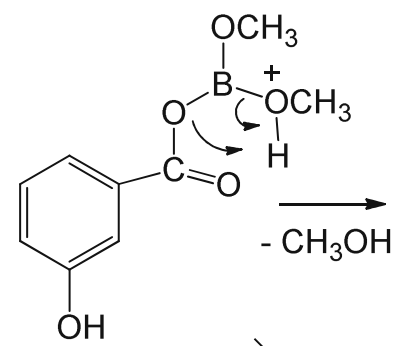<smiles>CO[B]OC(=O)c1cccc(O)c1</smiles>

$\mathrm{H}^{+}$migration

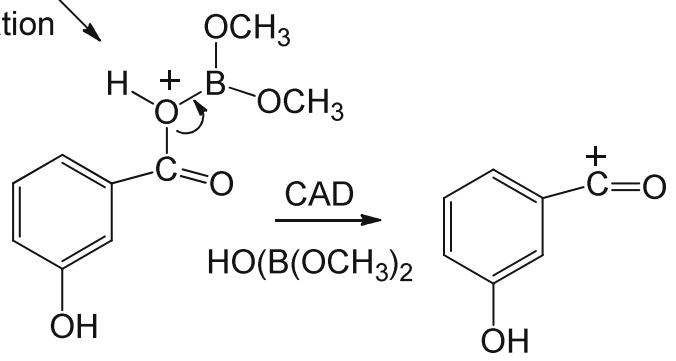

Scheme 6. 
of molecules of TMB consumed for the derivatization of both the functional groups. This is not true for the ortho- and para-isomers of hydroxyphenols that consume one TMB molecule for derivatization of each hydroxyl group. However, apart from the addition/elimination products, protonated ortho-hydroxyphenol also formed a stable adduct upon reaction with TMB. Thus, the three isomers of methoxyphenols and hydroxyphenols can be differentiated by reactions with TMB. Derivatization of both the functional groups in the ortho- and para-isomers indicates that in the methoxyphenols, the first derivatization is taking place at the hydroxyl group. This generates an acidic hydrogen, which enables the successive derivatization.

The ortho-isomer of hydroxyacetophenone and hydroxybenzoic acid can be differentiated from their meta- and paracounterparts but the latter isomers cannot be differentiated. The high PA of the ortho-hydroxyacetophenone hinders the initial proton transfer step. Hence, no reaction was observed between protonated ortho-hydroxyacetophenone and TMB. The ortho-hydroxybenzoic acid underwent complete derivatization with two molecules of TMB, along with a misleading formation of another product via intramolecular methanol loss from the doubly derivatized analyte. The meta- and para-isomers of hydroxyacetophenones and hydroxybenzoic acids formed only a singly derivatized product. However, subjecting the singly derivatized analytes to SORI-CAD resulted in the derivatization of the second functionality via a second methanol loss. The above reactivities suggest that the derivatization of the first functional group may not generate an acidic hydrogen for the successive derivatization to take place without collisional activation. This is proposed to take place via formation of stabilizing hydrogen bonding interactions that hinder attack at the acidic hydrogen of the singly derivatized hydroxybenzoic acids, and via protonation of the carbonyl oxygen for the hydroxyacetophenones.

The methoxyphenols, hydroxyphenols, hydroxyacetophenones, and hydroxybenzoic acids showed different reactivity toward TMB or different dissociation products upon CAD. These differences should facilitate the identification of these combinations of functional groups in unknown analytes. For example, a loss of $\mathrm{O}=\mathrm{B}\left(\mathrm{OCH}_{3}\right)_{2}$ upon $\mathrm{CAD}$ of the singly derivatized analyte occurs only for the meta- and parahydroxybenzoic acids, which may allow the identification of a benzoic acid moiety in unknown analytes (as long as it is not in the ortho-position). Further, almost all of the isomers undergo elimination of two methanol molecules from the TMB adducts of the analytes either during ion-molecule reactions or during following $\mathrm{CAD}$, thus revealing the presence of two functionalities. This approach may allow counting of functionalities in unknown oxygen-containing analytes.

The mass spectrometric methods discussed here allowed the differentiation of most of the regioisomers studied. Hence, this approach appears promising for situations where fast identification of regioisomers in complex mixtures is desired. Studies on additional aromatic regioisomers related to lignin degradation products are in progress.

\section{Acknowledgments}

The authors gratefully acknowledge Eli Lilly and Co. for providing partial financial support for this work. L.M.A. was supported as part of the Center for Direct Catalytic Conversion of Biomass to Biofuels (C3Bio), an Energy Frontier Research Center funded by the U.S. Department of Energy, Office of Science, Office of Basic Energy Sciences under Award Number DE-SC0000997.

\section{References}

1. Oliw, E.H., Garscha, U., Nilsson, T., Cristea, M.: Payne rearrangement during analysis of epoxyalcohols of linoleic and alpha-linolenic acids by normal phase liquid chromatography with tandem mass spectrometry. Anal. Biochem. 354, 111-126 (2006)

2. Sforza, S., Galaverna, G., Corradinin, R., Dossena, A., Marchelli, R.J.: ESI-Mass spectrometry analysis of unsubstituted and disubstituted betacyclodextrins: fragmentation mode and identification of the $\mathrm{AB}, \mathrm{AC}$, AD regioisomers. Am. Soc. Mass Spectrom. 14, 124-135 (2003)

3. Yamamura, H., Iwata, T., Kawai, M., Sato, A.: Electrospray ionization tandem mass spectrometry determined regioisomeric structures of disubstituted beta-cyclodextrin derivatives. Eur. J. Mass Spectrom. 12, 37-42 (2006)

4. Brodbelt, J.S.: Analytical applications of ion-molecule reactions. Mass Spectrom. Rev. 16, 91-110 (1997)

5. Kenttämaa, H.I., Cooks, R.G.J.: Identification of protonated betahydroxycarbonyl compounds by reactice collisions in tandem massspectrometry. Am. Chem. Soc. 111, 4122-4123 (1989)

6. Kenttämaa, H.I., Pachuta, R.R., Rothwell, A.P., Cooks, R.G.J.: Experimetnal study of the potential-energy surface of the protonated cyclohexene oxide cyclohexanone system - isomerization, dissociation, and ion molecule reactions of the isolated ions in the gas-phase. Am. Chem. Soc. 111, 1654-1665 (1989)

7. Staley, R.H., Corderman, R.R., Foster, M.S., Beauchamp, J.L.J.: Nucleophilic-attack on protonated oxiranes in gas-phase - identification of $\mathrm{C} 2 \mathrm{H} 5 \mathrm{O}+$ isomeric ion corresponding to protonated ethylene-oxide. Am. Chem. Soc. 96, 1260-1261 (1974)

8. Kass, S.R., Filley, J., Van Doren, J.M., DePuy, C.H.J.: Nitrous-oxide in gas-phase ion molecule chemistry - a versatile reagent for the determination of carbanion structure. Am. Chem. Soc. 108, 2849-2852 (1986)

9. Tolf, B.-R., Jiang, X.-Y., Wegmann-Szente, A., Kehres, L.A., Bunenberg, E., Djerassi, C.J.: Mass-spectrometry in structural and stereochemical problems .266. Enhanced structural determination of substituted porphyrins by ammonia desorption chemical ionization mass-spectrometry. Am. Chem. Soc. 108, 1363-1374 (1986)

10. Ranatunga, T.D., Kenttämaa, H.I.: Gas-phase reactions of dicoordinated boron cations with alcohols. Inorg. Chem. 34, 18-27 (1995)

11. Ranatunga, T.D., Kennedy, J.M., Kenttämaa, H.I.J.: Disubstituted boron cations cleave carbonyls. Am. Chem. Soc. 119, 5200-5207 (1997)

12. Ranatunga, T.D., Kenttämaa, H.I.J.: Dicoordinated boron cations dehydrate organic ethers in the gas-phase. Am. Chem. Soc. 114, 8600-8604 (1992)

13. Kempen, E.C., Brodbelt, J.J.: Use of trimethyl borate as a chemical ionization reagent for the analysis of biologically active molecules. Mass Spectrom. 32, 846-854 (1997)

14. Suming, H., Yaozu, C., Longfei, J., Shuman, X.: Stereochemical effects in mass-spectrometry .3. Detection of chirality by chemical ionization mass-spectrometry. Org. Mass Spectrom. 20, 7-10 (1986)

15. Somuramasami, J., Duan, P., Watkins, M.A., Winger, B.E., Kenttämaa, H.I.: Ion-molecule reactions of trimethylborate allow the mass spectrometric identification and counting of functional groups in protonated bifunctional oxygen-containing compounds and polyols. Int. J. Mass Spec. 265, 359-371 (2007)

16. Thoen, K.K., Gao, L., Ranatunga, T.D., Vainiotalo, P., Kenttämaa, H.I. J.: Stereoselective chemical ionization mass spectrometry: reactions of 
CH3OPOCH3+ with cyclic vicinal diols. Org. Chem. 62, 8702-8707 (1997)

17. Petucci, C., Guler, L., Kenttämaa, H.I.J.: Differentiation of stereoisomeric steroids by reactions with phosphenium ions. Am. Soc. Mass Spec. 13, 362-370 (2002)

18. Thompson, R.S., Guler, L.P., Nelson, E.D., Yu, Y.-Q., Kenttämaa, H.I.: Mechanistic study of stereoselective gas-phase reactions of phosphenium ions with cis- and trans-1,2-diaminochyclohexanes. J. Org. Chem. 67, 5076-5084 (2002)

19. Leavell, M.D., Kruppa, G.H., Leary, J.A.: Determination of phosphate position in hexose monosaccharides using an FTICR mass spectrometry: ion/molecule reactions, labeling studies, and dissociation mechanisms. Intl. J. Mass Spectrom. 222, 135-153 (2003)

20. Leavell, M.D., Kruppa, G.H., Leary, J.A.: Analysis of phosphate position in hexose monosaccharides using ion-molecule reactions and SORI-CAD on an FT-ICR mass spectrometer. Anal. Chem. 74, 26082611 (2002)

21. Gao, H., Petzold, C.J., Leavell, M.D., Leary, J.A.J.: Investigation of ion/molecule reactions as a quantification method for phosphorylated positional isomers: an FT-ICR approach. Am. Soc. Mass Spectrom. 14, 916-924 (2003)

22. Stephenson, J.L.J., McLuckey, S.A.: Counting basic sites in oligopeptides via gas-phase ion chemistry. Anal. Chem. 69, 281-285 (1997)

23. Stephenson, J.L.J., Schaaff, T.G., McLuckey, S.A.J.: Hydroiodic acid attachment kinetics as a chemical probe of gaseous protein ion structure: bovine pancreatic trypsin inhibitor. Am. Soc. Mass Spectrom. 10, 552 556 (1999)

24. Schaaff, T.G., Stephenson, J.L., McLuckey, S.A.J.: The reactivity of gaseous ions of bradykinin and its analogues with hydro and deuteroiodic acid. Am. Chem. Soc. 121, 8907-8919 (1999)

25. Gronert, S., O'Hair, R.A.: Gas phase reactions of trimethyl borate with phosphates and their non-covalent complexes. J. Am. Soc. Mass Spectrom. 13, 1088-1098 (2002)

26. Watkins, M.A., Price, J.M., Winger, B.E., Kenttämaa, H.I.: Ionmolecule reactions for mass spectrometric identification of functional groups in protonated oxygen-containing monofunctional compounds. Anal. Chem. 76, 964-976 (2004)

27. Watkins, M.A., Winger, B.E., Shea, R.C., Kenttämaa, H.I.: Ion-molecule reactions for the characterization of polyols and polyol mixtures by ESI/FTICR mass spectrometry. Anal. Chem. 77, 1385-1392 (2005)

28. Campbell, K.M., Watkins, M.A., Li, S., Fiddler, M.N., Winger, B., Kenttamaa, H.I.J.: Functional group selective ion/molecule reactions: mass spectrometric identification of the amido functionality in protonated monofunctional compounds. Org. Chem. 72, 3159-3165 (2007)

29. Watkins, M.A., WeWora, D.V., Li, S., Winger, B.E., Kenttämaa, H.I.: Compound screening for the presence of the primary N-Oxide functionality via ion-molecule reactions in a mass spectrometer. Anal. Chem. 77, 5311-5316 (2005)

30. Fu, M., Duan, P., Li, S., Habicht, C.S., Pinkston, S.D., Vinueza, R.N., Kenttämaa, H.I.: Regioselective ion-molecule reactions for the mass spectrometric differentiation of protonated isomeric aromatic diamines. Analyst 132, 452-454 (2008)

31. Duan, P., Gillespie, T.A., Winger, B.E., Kenttämaa, H.I.J.: Identification of the aromatic tertiary N-Oxide functionality in protonated analytes via ion/molecule reactions in mass spectrometers. Org. Chem. 73, 4888-4894 (2008)

32. Gronert, S., Huang, R., Li, K.H.: Gas phase derivatization in peptide analysis I: the utility of trimethyl borate in identifying phosphorylation sites. Int. J. Mass Spectrom. 231, 179-187 (2004)

33. Pyatkivskyy, Y., Ryzhov, V.: Coupling of ion-molecule reactions with liquid chromatography on a quadrupole ion trap mass spectrometer. Rapid Commun. Mass Spectrom. 22, 1288-1294 (2008)

34. Somuramasami, J., Winger, B.E., Gillespie, T.A., Kenttämaa, H. I., Am, J.: Identification and counting of carbonyl and hydroxyl functionalities in protonated bifunctional analytes by using solution derivatization prior to mass spectrometric analysis via ion-molecule reactions. Soc. Mass Spectrom. 21, 773-784 (2010)

35. Dunbar, R.C.: Infrared radiative cooling of gas-phase ions. Mass Spectrom. Rev. 11, 309-339 (1992)

36. Chen, L., Wang, T.C.L., Ricca, T.L., Marshall, A.G.: Phase-modulated stored wave-form inverse fourier-transform excitation for trapped ion mass-spectrometry. Anal. Chem. 59, 449-454 (1987)

37. Marshall, A.G., Wang, T.C.L., Ricca, T.L.J.: Tailored excitation for fourier-transform ion-cyclotron resonance mass-spectrometry. Am. Chem. Soc. 107, 7893-7897 (1985)

38. Gauthier, J.W., Trautman, T.R., Jacbson, D.B.: Sustained off-resonance irradiation for collision-activated dissociation involving fouriertransform mass-spectrometry - collision-activated dissociation technique that emulates infrared multiphoton dissociation. Anal. Chim. Acta 246, 211-225 (1991)

39. Bartmess, J.E., Georgiadis, R.M.: Empirical-methods for determination of ionization gauge relative sensitivities for different gases. Vacuum. 33, 149-153 (1983)

40. Leeck, D.T., Stirk, K.M., Zeller, L.C., Kiminkinen, L.K.M., Castro, L.M., Vainiotalo, P., Kenttämaa, H.I.J.: The long-lived radical cations of simple carbon esters isomerize to the lowest-energy structure. Am. Chem. Soc. 116, 3028-3038 (1994)

41. Thölmann, D., Grützmacher, H.-F.: Reactions of dihalobenzene radical cations with ammonia in the gas-phase - reactivity pattern for nucleophilic aromatic-substitution. J. Am. Chem. Soc. 113, 3281-3287 (1991)

42. Su, T., Chesnavich, W.J.: Parametrization of the ion-polar molecule collision rate-constant by trajectory calculations. J. Chem. Phys. 76, 5183-5185 (1982)

43. Frisch, M. J.; Trucks, G. W.; Schlegel, H. B.; Scuseria, G. E.; Robb, M. A.; Cheeseman, J. R.; Zakrzewski, V. G.; Montgomery, J. A. Jr.; Stratmann, R. E.; Burant, J. C.; Dapprich, S.; Millam, J. M.; Daniels, A. D.; Kudin, K. N.; Strain, M. C.; Farkas, O.; Tomasi, J.; Barone, V.; Cossi, M.; Cammi, R.; Menucci, B.; Pomelli, C.; Adamo, C.; Clifford, S.; Ochterski, J.; Petersson, G. A.; Ayala, P. Y.; Cui, Q.; Morokuma, K.; Malick, D. K.; Rabuck, A. D.; Raghavahari, K.; Foresman, J. B.; Cioslowski, J.; Ortiz, J. V.; Baboul, A. G.; Stefanov, B. B.; Liu, G.; Liashenko, A.; Piskorz, P.; Komaromi, I.; Gomperts, R.; Martin, R. L.; Fox, D. J.; Keith, T.; Al-Laham, M. A.; Peng, C. Y.; Nanayallara, A.; Gonzalez, C.; Challacombe, M.; Gill, P. M. W.; Johnson, B.; Chen, W.; Wong, M. W.; Andres, J. L.; Gonzalez, C.; Head-Gordon, M.; Replogle, E. S.; Pople, J. A. Gaussian O3, Revision C.O2, 2004 Gaussian Inc.: Wallington, C5, 2004

44. Bouchoux, G., Defaye, D., McMahon, T., Likholyot, A., Mó, M., Yáñez, M.: Structural and energetic aspects of the protonation of phenol, catechol, resorcinol, and hydroquinone. Chem. Eur. J. 8, 29002909 (2002)

45. Bjarnason, A., Taylor, J.W., Kinsinger, J.A., Cody, R.B., Weil, D.A.: Isomer discrimination of disubstituted benzene-derivatives through gasphase iron(I) ion reactions in a fourier-transform mass spectrometer. Anal. Chem. 61, 1889-1894 (1989)

46. Xue, K.E.-H., Xu, W., Yin, S.-Y.J.: Electrochemical determination of dihydroxybenzene isomers at the carbon-atom-wire-modified electrode. Electrochem. Soc. 154, F147-F151 (2007)

47. Brodbelt, J., Lious, C.-C., Donovan, T.: Selective adduct formation by dimethyl ether chemical ionization in a quadrupole ion trap massspectrometer and a conventional ion-source. Anal. Chem. 63, 12051209 (1991)

48. Understanding Mass Spectra: A Basic Approach, Smith, R.M., 2nd ed.; John Wiley and Sons: Hoboken, NJ, 2004.

49. de Koster, C.G., Niemann, G.J., Heerma, W.: Fast-atom-bombardment mass-spectrometry of Hydroxybenzoic acids. Fresenius J. Anal. Chem. 323, 321-325 (1986) 